\title{
EDITORIAL
}

\section{The journey of a thousand miles}

\author{
A. Bush and J. Davies
}

$\mathbf{T}$ reatment of cystic fibrosis $(\mathrm{CF})$ is in a state of transition. $25 \mathrm{yrs}$ ago the emphasis was on the downstream consequences of the disease, the prevention (as far as possible) and treatment of airway infection and inflammation, malabsorption, diabetes, liver disease and the many complications, such as bone disease and subclinical insulin deficiency, that have emerged as longevity has increased. In 1989, the CF gene (CF transmembrane regulator; CFTR) was localised to the long arm of chromosome $7[1-3]$ and confirmed to be a chloride ion transporter. This has stimulated an explosion of knowledge about the basic biology of CF. Amongst the many advances, the recognition [4] that there are different classes of mutations (table 1) has raised the possibility of genotype specific therapy, not merely for $\mathrm{CF}$, but also for other genetic diseases. Perhaps in the future we will be asking not which gene locus is affected in a given patient, but which class of problem is the issue. Over-riding premature stop codons (class 1 mutations) may potentially lead to an improvement in other respiratory diseases (e.g. primary ciliary dyskinesia) and nonrespiratory conditions, such as Duchenne muscular dystrophy. We stand on the threshold of a new exciting age of treatments aimed at the basic molecular defect in $\mathrm{CF}$, far upstream from the catastrophic consequences of CFTR dysfunction on end organs.

However, clear-headed consideration is warranted amongst the excitement. Despite the brilliance of the scientific insights which have sprung up from the discovery of CFTR, $>20 \mathrm{yrs}$ later it is sobering to reflect that to date, no single CF patient has derived clinical benefit from these molecular discoveries. Thankfully, the speculation of the early 1990s, that gene therapy would cure $\mathrm{CF}$ within $5 \mathrm{yrs}$, has been replaced by more realistic prognostications. There are numerous promising candidates for genotype specific therapies (table 1), including gene therapy (which is of course potentially applicable irrespective of genotype), $\mathrm{PTC}_{124}$ [5], vertex compounds (VX809 and VX-770) [6, 7], and a whole array of other CFTR correctors (which increase CFTR trafficking to the cell membrane) and potentiators (which increase CFTR activity when it has reached the apical cell membrane) [6]. However, at the moment they are just that, promising candidates, which have shown proof of concept biological activity in cellular, animal and some short-term human studies, but, as yet, no medium-term therapeutic benefit.

The most common CFTR mutation in white races is $\Delta \mathrm{F}_{508}$, a class II mutation which leads to abnormal CFTR protein

Dept of Paediatric Respiratory Medicine, Royal Brompton Hospital, London, UK.

CORRESPONDENCE: A. Bush, Dept of Paediatric Respiratory Medicine, Royal Brompton Hospital, Sydney Street, London SW3 6NP, UK, E-mail a.bush@rbh.nthames.nhs.uk largely being destroyed intracellularly, and not reaching the apical cell membrane in any quantity. There has long been tantalising evidence that mutant $\Delta \mathrm{F}_{508}$ CFTR has chloride channel activity, for example when cooled to $26^{\circ} \mathrm{C}$ in the Xenopus oocyte model [8], suggesting that if it could be made to escape intracellular destruction, then some amelioration of disease may be possible. It may be that this strategy might be augmented by combining a corrector with a potentiator, a compound which increases the activity of $\Delta \mathrm{F}_{508}$ CFTR at the apical cell membrane.

Selective inhibitors of the cyclic guanosine monophosphatedependent phosphodiesterase type 5 (PDE-5) have been shown to be useful in erectile dysfunction and pulmonary hypertension, albeit often at the cost of systemic side-effects. There is increasing evidence that they can correct chloride transport both in $\Delta \mathrm{F}_{508}$ CFTR cell lines and $\Delta \mathrm{F}_{508}$ CF mice $[9,10]$. In the animal studies performed to date, these inhibitors have had to be administered parenterally, which is clearly not ideal when the target is the airway epithelium. In this issue of the European Respiratory Journal, LUBAMBA et al. [11] have moved this field forward with a series of well-performed and technically very challenging experiments in $\Delta \mathrm{F}_{508} \mathrm{CF}$ mice. In summary, they report: 1) that nebulising the mice in a specially constructed restraining chamber with any of the PDE-5 inhibitors sildenafil, vardenafil or tadalafil led to correction of nasal chloride transport; 2) correction was greatest with taladafil and least (although still highly significant) with sildenafil; and 3) the effects of vardenafil, but not sildenafil, lasted $\geqslant 8 \mathrm{~h}$ after a single treatment. How do these results move the field forward?

There are a number of technical issues which need to be confronted. We lack any dose-response curves for any of the inhibitors, and a more complete description of duration of action is needed. Although the authors have clearly demonstrated nasal PDE changes in the mice, itself by no means a trivial exercise, they have neither satisfactorily confirmed that these were achieved by the inhalational route, nor that any active substance has reached the lower airway by any route. The mouse is an obligate nose breather, and it seems likely that there was aerosol nasal deposition, but the possibility remains that the mice absorbed the inhibitors after swallowing material deposited in the pharynx or per-orally by licking deposited material off their fur, or even by direct transcutaneous absorption, albeit this last being extremely unlikely. Lower airway deposition is a complex challenge, particularly in the presence of airway disease and even with modern nebulisers, and there is much work to be done before any of these inhibitors can be brought into human trials using the airborne route. Furthermore, the lower airway has a rich blood supply, particularly in CF [12], and even if there is successful 
TABLE 1 Potential genotype specific therapies for cystic fibrosis

\begin{tabular}{|c|c|c|c|}
\hline Class number & Exemplar mutation & Molecular consequence & Potential therapy \\
\hline Class I & G542X & No CFTR synthesis: premature stop codon & PTC $_{124}$ \\
\hline Class III & G551D & $\begin{array}{l}\text { CFTR reaches apical membrane, but channel regulation is abnormal } \\
\text { (open time is reduced) }\end{array}$ & VX-770 \\
\hline Class IV & R334W & CFTR reaches apical membrane, but channel conductivity is reduced & \\
\hline
\end{tabular}

significant lower airway deposition, absorption into the circulation and systemic side-effects remain a real possibility. The final issue is that CFTR is a multifunctional protein, and the most likely pathophysiological hypothesis for CF lung disease posits that epithelium sodium channel (ENaC) overactivity secondary to loss of modulation by CFTR is the key abnormality $[13,14]$, and ENaC function was not altered at all by PDE-5 inhibition.

Nonetheless, this study is a small but significant step forward on the journey to what must be the ultimate aim, that of diagnosis of CF by newborn screening and the institution in very young babies of specific treatment which will correct CFTR dysfunction, rather than cope with its consequences. In this context, both safety and, in particular, making sure there are no unpleasant side-effects of treatment will be paramount. The use of the inhaled route is significantly more likely to achieve this; it is difficult to think that the early institution of lifelong oral treatment with these potent medications will be acceptable. So the strengths of this contribution are to highlight that a systemic approach may not be necessary and that vardenafil, at least, may have a sufficiently long duration of action to make it a practical therapeutic proposition. However, much painstaking work remains to be done. The first single step on the journey of a thousand miles is indeed significant, but the distance to journey's end must be clearly perceived.

\section{STATEMENT OF INTEREST}

Statements of interest for both authors can be found at www.erj. ersjournals.com/site/misc/statements.xhtml

\section{REFERENCES}

1 Rommens JM, Iannuzzi MC, Kerem B, et al. Identification of the cystic fibrosis gene: chromosome walking and jumping. Science 1989; 245: 1059-1065.
2 Riordan JR, Rommens JM, Kerem B, et al. Identification of the cystic fibrosis gene: cloning and characterization of complementary DNA. Science 1989; 245: 1066-1073.

3 Kerem B, Rommens JM, Buchanan JA, et al. Identification of the cystic fibrosis gene: genetic analysis. Science 1989; 245: 1073-1080.

4 Welsh MJ, Smith AE. Molecular mechanisms of CFTR chloride channel dysfunction in cystic fibrosis. Cell 1993; 73: 1251-1254.

5 Kerem E, Hirawat S, Armoni S, et al. Effectiveness of PTC124 treatment of cystic fibrosis caused by nonsense mutations: a prospective phase II trial. Lancet 2008; 372: 719-727.

6 Jones AM, Helm JM. Emerging treatments in cystic fibrosis. Drugs 2009; 69: 1903-1910.

7 Van Goor F, Hadida S, Grootenhuis PD, et al. Rescue of CF airway epithelial cell function in vitro by a CFTR potentiator, VX-770. Proc Natl Acad Sci USA 2009; 106: 18825-18830.

8 Denning GM, Anderson MP, Amara JF, et al. Processing of mutant cystic fibrosis transmembrane conductance regulator is temperaturesensitive. Nature 1992; 358: 761-764.

9 Dormer RL, Harris CM, Clark Z, et al. Sildenafil (viagra) corrects DeltaF508-CFTR location in nasal epithelial cells from patients with cystic fibrosis. Thorax 2005; 60: 55-59.

10 Lubamba B, Lecourt H, Lebacq J, et al. Preclinical evidence that sildenafil and vardenafil activate chloride transport in cystic fibrosis. Am J Respir Crit Care Med 2008; 177: 506-515.

11 Lubamba B, Lebacq J, Reychler G, et al. Inhaled phosphodiesterase type 5 inhibitors restore chloride transport in cystic fibrosis mice. Eur Respir J 2011; 37: 72-78.

12 McCullagh A, Rosenthal M, Wanner A, et al. The bronchial circulation-worth a closer look: A review of the relationship between the bronchial vasculature and airway inflammation. Pediatr Pulmonol 2010; 45: 1-13.

13 Matsui H, Grubb BR, Tarran R, et al. Evidence for periciliary liquid layer depletion, not abnormal ion composition, in the pathogenesis of cystic fibrosis airways disease. Cell 1998; 95: 1005-1015.

14 Tarran R, Button B, Picher $\mathrm{M}$, et al. Normal and cystic fibrosis airway surface liquid homeostasis. The effects of phasic shear stress and viral infections. J Biol Chem 2005; 280: 35751-35759. 